


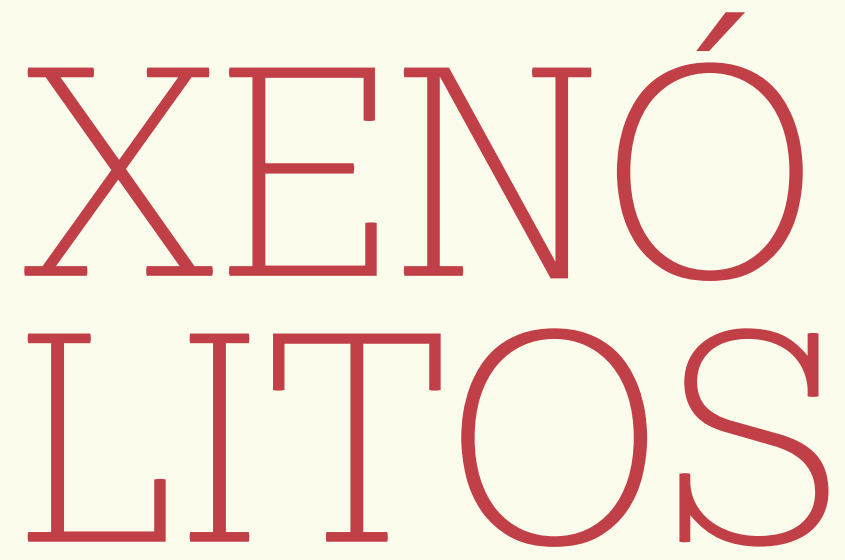

Fragmento de rocha preexistente, envolvido numa rocha magmática. 


\section{DOIS POEMAS DE HEINRICH HEINE \\ $\mathrm{E}$ \\ SEIS POEMAS DE FRANK WEDEKIND}

- TRADUÇÃO E NOTAS VINÍCIUS MARQUES PASTORELLI 


\section{LOTOSBLUME}

HEINE

Wahrhaftig, wir beide bilden

Ein kurioses Paar,

Die Liebste ist schwach auf den Beinen,

Der Liebhaber lahm sogar.

Sie ist ein leidendes Kätzchen,

Und er ist krank wie ein Hund,

Ich glaube, im Kopfe sind beide

Nicht sonderlich gesund.

Sie sei ein Lotosblume,

Bildet die Liebste sich ein;

Doch er, der blasse Geselle,

Vermeint der Mond zu sein.

Die Lotosblume erschliesset

Ihr Kelchlein im Mondenlicht,

Doch statt des befruchtenden Lebens

Empfängt sie nur ein Gedicht. 


\title{
FLOR DE LÓTUS ${ }^{1}$
}

\author{
HEINE
}

Cândido, confesso: fazemos

Um belo par.

A donzela manca das pernas,

O rapaz deu de coxear.

Ela, bichana que padece.

Ele, doente como um cão.

$\mathrm{E}$, cá entre nós, eu vos digo:

Da cabeça não são muito sãos.

"Bela como a flor de lótus",

Ela ao espelho se aprecia.

E ele, pálido, sobe aos céus.

É a lua que surgia.

Como cálice à luz da lua, eis

A flor de lótus sobre a rama.

Em vez de vida suculenta,

Um poema se lhe derrama.

[1] Desfazendo clichês líricos por meio de um olhar mundano ele mesmo sujeito a crítica - de modo que figuração e perspectiva se suspendem mutuamente, um como idealismo, outro como maledicência pequeno-burguesa, ambos nivelados ao final à mesma infertilidade a que foi relegada a poesia num mundo pragmático - esse poema irônico, que se desenrola como uma espécie de idílio rebaixado, trabalha com o descompasso entre a autoimagem do casal e a suposta verdade insinuada pelo eu-lírico.

Dessa interpretação derivam alguma escolhas de tradução.

Sendo a ironia a tônica principal, trocamos o mais neutro kurioses (curioso) pelo sarcástico "belo" e wahrhaftig (verdadeiramente, sinceramente) por "cândido".

No mesmo sentido, criamos imagens procurando dar conta da vaidade da amada e do enlevo fácil do amante. A formulação do original diz, no discurso indireto, que ela se imagina bela como uma flor de lótus, mas sugere (pelo verbo sich einzubilden, "imaginar-se") que ela pode não ser (Sie sei ein Lotosblume,/ bildet die Liebste sich ein). Na figuração criada, ela se mira ao espelho e diz a frase, no discurso direto. 0 mesmo no que se refere ao amante: no original, enlevado pela paixão e platonicamente distante, ele "acredita ser a lua" (Vermeint der Mond zu sein); em nossa tradução, reforçamos o humor do poema, apenas tomando essa mesma ideia ao pé da letra ("sobe, pálido, aos céus"). 


\section{"SAPHIREN SIND DIE AUGEN DEIN"}

HEINE

Saphiren sind die Augen dein

Die lieblichen, die süssen.

O, dreimal glücklich ist der Mann,

Den sie mit Liebe grüssen.

Dein Herz, es ist ein Diamant,

Der edle Lichter sprühet.

O, dreimal glücklich ist der Mann,

Für den es lieben glühen.

Rubinen sind die Lippen dein,

Mann kann nicht schönre sehen.

$O$, dreimal glücklich ist der Mann,

Dem sie die Liebe gestehen.

O, kennt ich nur den glücklichen Mann,

$O$, dass ich ihn nur fände,

So recht allein im grünen Wald,

Sein Glück hat bald ein Ende. 


\title{
"DE SAFIRA SÃO TEUS OLHOS"
}

\author{
HEINE
}

De safira são teus olhos,

Os mais dóceis e amáveis.

Ó, bem-aventurado seja aquele

Que o amor te dedicares.

No teu peito mora pérola ${ }^{2}$

Cuja nobre luz cintila.

$\mathrm{O}^{3}$, bem-aventurado seja aquele

Para quem a gema brilha.

De rubis são os teus lábios,

Os mais belos sobre a Terra.

Ó, bem-aventurado seja aquele

Que todo amor lhes dera.

Ó, se um dia encontro o incauto.

Ó, rapaz que a ventura brinda.

Para o verde bosque o arrasto,

Sumirá na luz que finda.

[2] Pensando que se trata aqui de outro poema irônico de amor, mas desta vez derivado de um mote do tesouro popular - tomado é claro segundo uma lógica de falsificação que desmente tudo o que pretende ser autêntico numa sociedade regida por dinheiro -, não haveria grande perda em trocar o campo mineralógico pelo das preciosidades de butique, ao recriarmos Diamant com "pérola". Uma vez conduzido o mesmo locus ao extremo, é uma lógica semelhante que faz com que o eu lírico parta da posição de admirador platônico (que contudo aquilata seu objeto de desejo) e chegue a sugerir o assassinato da concorrência, no quarteto final. Não é por outra razão que Heine vem sendo lido recentemente na mesma linha de seu contemporâneo, o Baudelaire de Le vin de l'assassin. Esse, quase um poema de amor desentranhado do depoimento inebriado do autor de um crime passional de notícias populares. Nesse sentido, ver OEHLER, Dolf. Quadros Parisienses. São Paulo: Companhia das Letras, 2007.

[3] Uma argúcia estrutural do poema é dizer em três estrofes "três vezes bem aventurado seja aquele" e guardar a conclusão demolidora para a quarta estrofe (assim ninguém pode dizer que o amor não foi três vez louvado...). De fato é um truque interessante, que soma ainda mais premeditação à malícia da voz enunciativa. No entanto, recriá-lo como "triplamente bem-aventurado" implicaria quebrar a leveza do verso com um advérbio muito extenso e de inequívoca origem culta. Por isso ficamos simplesmente com um "Ó". 


\section{DER GEFANGENE}

WEDEKIND

Oftmals hab' ich nachts im Bette

Schon gegrübelt hin und her,

Was es denn geschadet hätte,

Wenn mein Ich ein Andrer wär'.

Höhnisch raubten meine Zweifel

Mir die tolle Antwort zu:

Nichts geschadet, dummer Teufel,

Denn der Andre wärest du!

Hilflos wälzt' ich mich im Bette

Und entrang mir dies Gedicht,

Rasselnd mit der Sklavenkette,

Die kein Denker je zerbricht.

[4] Neste como noutros poemas consideramos a estrita aderência ao esquema rímico (neste caso abab) um critério passível de ser rompido. A métrica, embora nem sempre coincidente (como por exemplo em Flor de lótus), é mantida, mas com a maleabilidade que todo poema, salvo em casos deliberados, admite 
O PRISIONEIRO

WEDEKIND

Volta e meia já na cama,

Pensamentos eu remoo:

Que seria desta vida,

Se o eu meu fora de um outro?

De respostas, escarninho,

Meu pensar me deixa nu:

Nada fora, diabinho,

Se esse outro foras tu!

Desarmado estou na cama

E chacoalho estas correntes,

Que um poema não destranca,

Nem há sábio que arrebente. 


\section{BAJAZZO}

WEDEKIND

Seltsam sind des Glückes Launen

Wie kein Hirn sie noch ersann,

Dass ich meist vor lauter Staunen

Lachen nicht noch weinen kann!

Aber freilich steht auf festen

Füssen selbst der Himmel kaum,

Drum schlägt auch der Mensch am besten

Täglich seinen Purzelbaum.

Wem die Beine noch geschmeidig, Noch die Arme schmiegsam sind, Den stimmt Unheil auch so freudig, Dass er's innig lieb gewinnt! 
BAJAZZO5

WEDEKIND

Caprichosa é a fortuna.

Testa alguma a acompanha.

Tanto que ante algum estalo,

Todo riso ou choro estanca.

Mas nem mesmo o próprio céu

Sobre os pés se equilibra.

Nesta vida cavalgamos

Cambalhotas dia a dia.

Se as pernas são bem destras

E os braços ${ }^{6}$ mais um pouco,

A desgraça bate palmas

E acalanta seu sufoco!

[5] Mantivemos o título original em italiano, pois acreditamos haver aí alguma ressonância intencional da história do teatro alemão, segundo a qual na Áustria - e em geral por influência do Sul menos sujeito ao Protestantismo -, a comédia popular sobreviveu ao processo de consolidação do drama burguês, mais associado ao Norte. Nesse sentido ver 'Ligeiro excurso pela Áustria' In: ROSENFELD, Anatol. Teatro Alemão - 1ª̣ parte, esboço histórico. São Paulo: Editora Brasiliense, 1968. pp.71-81.

[6] Neste poema em que, como de praxe em Wedekind, o universo do circo e das atrações populares estabelece um filtro contra o idealismo, a fim de se tratar tanto das tensões do espírito quanto das questões da vida material, há um jogo entre trágico e cômico, pensamento e corporalidade, espírito e matéria, Céu e Terra. Digamos que as irresoluções do sentimento, tanto quanto as da precariedade de sentido e de condições de vida, são contrabalanceadas pelo apego à graça da existência mundana, entrevista - por meio da metáfora do acrobata e do palhaço - nos expedientes com que os pobres vão tocando a vida. Essa parece ser a matéria que, em seu número de palhaço, o eu lírico quer celebrar, chegando inclusive a inverter potencialmente a ordem social, ou para dizê-lo num trocadilho ao seu gosto, "pô-la de pernas para o alto'. Diante desse plano de sentido, um detalhe fundamental do original é que o radical da palavra "pobre" é semelhante ao da palavra "braço" em alemão, Arm-. E isso justamente num verso em que são invertidas as propriedades de rigidez das pernas - parte musculosa da anatomia, que sustenta ou exerce pressão - e de destreza dos braços - que constroem algo ou expressam-no por gestos. Não foi possível reconstituir esse trocadilho. No entanto, para não perder o sentido, confiamos no ar de sabedoria popular que o dístico "nesta vida cavalgamos/ cambalhotas dia a dia" procurou recriar na segunda estrofe. 


\section{AN EINEN DICHTER}

WeDEKIND

- Dein Schaffen war wie Gold so echt, Solang du Modekram geschaffen.

Du gabst dem menschlichen Geschlecht Urechten Plunder zu begaffen.

Doch seit ein reineres Idol

Dein ruhmbedürftig Herz begeistert, Wie ward dein Schaffen falsch und hohl, Aus eitel Phrasenschwulst gekleistert 


\title{
A UM POETA
}

\author{
WEDEKIND
}

- Vero teu achado como ouro

Quando modas te punhas a inventar, Por legares aos homens deste mundo

Um lixo verdadeiro a contemplar.

Mas desde que um espírito elevado

Com fama amaciou teu coração, No oco empastelou-se teu achado:

São frases de efeito em maçapão7.

[7] Num poema de Wedekind que pondera sobre as relações contraditórias entre kitsch e matéria poética elevada, todo o plano de sentido que encerra o poema ("empastelar", "maçapão") foi reconstruído de acordo com a ideia do jovem Brecht sobre a "arte culinária" (ou seja, a arte de consumo rápido), a ser contraposta à aura de autenticidade da arte em crise. Pensamos ser possível fazê-lo porque o segundo foi declaradamente discípulo do primeiro. E, ademais, porque o verbo kleistern, em primeira instância "colar", pode de fato significar "grudar com massa". Sobre a "arte culinária" em Brecht, ver sessão sobre o declínio do antigo teatro. Schriften zum Theater I, Gesammelte Werke 15. Frankfurt am Main: Suhrkamp, 1967. 


\section{DER TANTENMÖRDER}

WEDEKIND

Ich habe meine Tante geschlachtet

Meine Tante war alt und schwach.

Ich hatte bei ihr übernachtet

Und grub in den Kisten-Kasten nach.

Da fand ich Goldenen Haufen

Fand auch im Papieren gar viel

Und hörte die alte Tante schnaufen

Ohn' Mitleid und Zartgefühl.

Was nutzt es, dass sie sich noch härme

Nachts war es rings um mich her-

Ich stiess ihr den Dolch in de Därme,

Die Tante schnaufte nicht mehr.

Das Geld war schnell zu tragen, viel schwerer die Tante noch.

Ich fasste sie bebend am Kragen

Und stiess sie ins tief Kellerloch. -

Ich habe meine Tante geschlachtet

Meine Tante war alt und schwach;

Ihr aber, o Richter, ihr trachtet

Meiner blühenden Jugend-Jugend nach. 


\section{O ASSASSINO DA TIA}

WEDEKIND

Matei minha tia esta noite,

Ela estava pela hora da morte;

Armei a tocaia na sala

Fucei em seu baú da sorte ${ }^{8}$.

Ali encontrei pilhas de ouro,

Papeis variados também;

Ouvindo a velha que arfava

Sem pena, desprezo ou desdém.

De que servia o seu lamentar

Que dia e noite importunava? -

Meti-lhe o punhal na jugular

E a titia já não mais arfava.

Foi bem difícil levar o dinheiro

E a velha, pesada, ainda mais.

Mas se ela tremia em meu colo,

No porão jazia em paz. -

Matei minha tia esta noite

Ela estava pela hora da morte;

Veja lá, seu juiz, se vai perseguir

O feito da minha Jovem-Jovem.

[8] Há dificuldades em compreender o sentido da duplicação de termos em Kisten-Kasten (literalmente caixa-caixa) e Jugend-Jugend (juventude-juventude), que formam uma espécie de paralelismo secreto encerrando o poema. Uma interpretação possível deste poema permite enxergá-lo em dois planos. A) Como uma espécie de elaboração-limite do conhecido locus romântico em que um jovem, posto em teste pelo destino na convivência clandestina com alguma entidade mágica, quebra o encanto iniciático cedendo à tentação de roubar suas preciosidades. (Nesse sentido, ver: "O loiro Eckbert" In: TIECK, Ludwig. Feitiço de amor e outros contos. São Paulo: Hedra, 2009, pp.23-51.). B) Sendo Wedekind alguém que elaborou suas canções em cabarés, onde vigorava uma linguagem às vezes infantilizada - na verdade, linguagem marcada por uma espécie de inventiva e ingênua pecaminosidade -, ele contribuiu para esse tipo de diç̧ão, de que as silabadas, onomatopeias e esvaziamentos absurdos de significantes fazem parte. Pode-se imaginar o assassinato da tia, nesse sentido, como uma espécie de paródia sangrenta do Romantismo, apresentado ao juiz. Daí veio nossa escolha de "baú da sorte" para Kisten-Kasten e de "Jovem-Jovem" para Jugend-Jugend. 


\section{DIE WETTERFAHNE}

WeDEKIND

Du auf deinem höchsten Dach,

Ich in deiner Nähe;

Doch die wahre Liebe, ach,

Schwankt in solcher Höhe.

Du in deinem Herzen leer,

Ich in blindem Wahne -

Dreh dich hin, dreh dich her,

Schöne Wetterfahne!

Unterhaltend pfeift der Wind,

Bläst uns um die Ohren;

Von des Himmels Freuden sind

Keine noch verloren!

Glaubst du, dass verliebt ich bin,

Weil ich dich ermahne?

Dreh dich her, dreh dich hin,

Schöne Wetterfahne!

Drehn wir uns auf hohem Turm

Immer frisch und munter!

Ach der erste Wintersturm

Schleudert dich hinunter.

Wenn dann auch verflogen war,

Was ich jetzt noch ahne...

Dreh dich hin, dreh dich her,

Schöne Wetterfahne! 
O CATAVENTO

\author{
WEDEKIND
}

Tu, que vives lá no alto

e eu a ti pegado;

Das alturas todo amor

tende para baixo.

O teu peito está vazio, eu em devaneio

- Gira aí, gira aqui, gira, catavento!

Sopra o vento brincalhão, estoura ao pé do ouvido. Ah, da paz na imensidão nada está perdido.

Cuidas eu te quero bem porque te cortejo?

- Gira aqui, gira aí, gira, catavento!

Gira numa alta torre a doce amizade.

Peço pra que te derrube A prima tempestade.

Ai quem dera fosse vento o que ainda almejo...

- Gira, aí; gira aqui, gira, catavento! 


\section{DER ANARCHIST}

WEDEKIND

Reicht mir in der Todesstunde

Nicht in Gnaden den Pokal!

Von des Weibes heissem Munde

Lasst mir trinken noch einmal!

Mögt ihr sinnlos euch berauschen

Wenn mein Blut zerrinnt im Sand.

Meinen Kuss mag sie nicht tauschen,

Nicht für Brot aus Henkershand.

Einen Sohn wird sie gebären,

Dem mein Kreuz im Herzen steht,

Der für seiner Mütter Zähren

Eurer Kinder Häupter mäht. 
O ANARQUISTA

WEDEKIND

Vais me achar na hora extrema,

Não em louros e troféus!

Dê-me mais um beijo, ó fêmea,

Na mortalha, sob um véu!

Quando expiro comemoras,

Se meu sangue a terra enxuga.

Mas meu beijo ela não troca,

Nem por pão na cela escura.

Filho meu ela amamenta

- Esse leva a cruz dos fortes.

Colherá da mãe as penas

e as cabeças de tua prole. 
VINÍCIUS MARQUES PASTORELLI - Mestre no Programa de Pós-Graduação em Teoria Literária e Literatura Comparada pela FFLCH-USP.

vmarquespastor@gmail.com

\section{FONTE:}

WEDEKIND, Frank. Ich liebe nicht den Hundetrab - Gedichte, Bänkellieder, Balladen. Klassische Kleinebühne. Berlin: Henschelverlag, 1971.

Para "Saphiren sind die Augen dein",

HEINE, Heinrich. Heinrich Heine's Sämmtliche Werke. Band 15. Hamburg: Hoffmann und Campe, 1873.

Para Lotosblume,

HEINE, Heinrich. Sammtliche Werke. Nachlese zu Gedichte (1831-1848).

München: Kindler, 1964. 